\title{
O BEM VIVER EM SOCIEDADE: NOTAS SOBRE O VIRTUOSO E A VIRTUDE NA OBRA DE ARISTÓTELES
}

\section{RESUMO}

Neste artigo, que parte de princípios discutidos em Ética a Nicômaco, de Aristóteles (2006), abordaremos algumas das diversas formas de virtude, bem como o exercício delas, ou seja, a prática contínua (rex) de atos virtuosos que levam a criação de um círculo virtuoso, necessário à moral grega e a vida dentro de sua sociedade. Para tal, precisaremos reconhecer e abordar 0 conceito de virtude, caro a filosofia do pensador estagirita, bem como a coragem, a temperança, a liberdade, a magnificência, a magnanimidade, a honra, a calma, o espirituoso e a justiça. Tal construção textual se justifica nos dias atuais como uma reflexão sobre a vida na sociedade brasileira diante das discussões sobre os valores morais propalados desde os cidadãos mais simples aos brasileiros que ocupam cargos eletivos na política nacional.

Palavras Chave: Aristóteles. Virtude. Vida em Sociedade. Ética. Moral.

\section{THE WELL TO LIVE IN SOCIETY: NOTES ABOUT THE VIRTUOUS AND VIRTUE IN THE WORK OF ARISTOTLE}

\section{RESUME}

In this article, which starts from the principles discussed in Nicomachean Ethics, by Aristotle (2006), we will approach some of the diverse forms of virtue, as well as their exercise, that is, the continuous practice (rex) of virtuous acts that lead to the creation of a virtuous circle, necessary for Greek morality and life within its society. For this, we will need to recognize and discuss the concept of virtue, dear to the philosophy of the Stagirite thinker, as well as courage, temperance, freedom, magnificence, magnanimity, honor, calm, witty and justice. Such textual construction is justified nowadays as a reflection on life in Brazilian society in the face of discussions about the moral values propagated from the simplest citizens to the Brazilians who occupy elective positions in national politics.

Keywords: Aristotle: Virtue. Society Life. Ethic. Moral.

\footnotetext{
1 Atua como professor do Departamento de Teorias e Fundamentos da Educação da Universidade Federal do Amazonas. Email: fabiosouzaclima@gmail.com
} 


\section{EL BIEN A VIVIR EN SOCIEDAD: NOTAS SOBRE VIRTUD Y VIRTUD EN EL TRABAJO DE ARISTOTLE}

\section{RESUMEN}

En este artículo, que parte de los principios discutidos en Ética de Nicomache, por Aristóteles (2006), abordaremos algunas de las diversas formas de virtud, así como su ejercicio, es decir, la práctica continua (rex) de actos virtuosos que conducen a la creación de Un círculo virtuoso, necesario para la moralidad griega y la vida dentro de su sociedad. Para hacer esto, necesitaremos reconocer y discutir el concepto de virtud, querida la filosofía del pensador estagirita, así como el coraje, la templanza, la libertad, la magnificencia, la magnanimidad, el honor, la calma, el ingenio y la justicia. Tal construcción textual se justifica hoy en día como una reflexión sobre la vida en la sociedad brasileña frente a las discusiones sobre los valores morales propagados desde los ciudadanos más simples hasta los brasileños que ocupan cargos electivos en la política nacional.

Palabras clave: Aristóteles. Virtud. La vida de la sociedad. Principio moral. Moral.

\section{INTRODUÇÃO - ANSEIOS E ANGÚSTIAS}

O conceito que exprimia o ideal de formação social e educacional dos gregos originalmente é construído sobre o período homérico (entre os séculos XII e VIII a.C.), estando contido no termo Aretê (que significa perfeição ou excelência de uma coisa). Em síntese, no período homérico, esse termo representava o conjunto de qualidades físicas, espirituais e morais, identificadas com os ideais de bravura, heroísmo, honra e glória em batalhas.

Com o fim do período homérico e início do período arcaico (VIII a.C. ao século VI a.C), porém, essa ideia de formação educacional do grego se alargou na mesma medida em que o conceito de Polis começava a exigir um novo tipo de homem grego. Além das exigências físicas e morais, o novo homem deveria se prestar também ao exercício e participação das decisões administrativas da cidade. No final desse período, o pensamento educacional dos pré-socráticos, se desvinculando da esfera mítica e se aproximando da phyisis, cujos dados empíricos e de raciocínio se tornaram bases de 
suas formulações filosóficas, contribuíram de sobremaneira para o desenvolvimento desse novo cidadão (JAEGER, 2013).

Tratava-se da construção de um novo ethos na concepção da formação do homem grego. Se antes o ideal de homem, residia na coragem da ação em batalha, agora era necessário um homem capaz de dividir a responsabilidade de gestão da cidade-estado. Em outras palavras, o homem grego foi forçado a tornar-se politikos, tal como percebemos no pensamento de Aristóteles, quando escreve que só há deliberação e decisão das coisas que estão em nosso poder (CANIVEZ, 1991).

Por sua vez, surge um novo conceito de educação e formação desse cidadão, chamado de Paideia. De forma direta, a Paideia visava atender aos pré-requisitos supracitados do novo homem grego, educando a criança para a harmonia, para a moderação e para a temperança consigo mesma, além da virtuosa concórdia na vida dentro da cidade (MATOS, 1997). Contudo, a definição desse conceito é difícil, surgindo ainda sobre esse conceito uma série de interpretações de como deveria funcionar a Paideia.

Segundo Werner Jaeger argumenta (2013), assim como são vários outros conceitos abrangentes, a dificuldade de definir a Paideia resiste em sua característica de se deixar encerrar numa concepção abstrata. Enquanto Henri-Irénée Marrou (1973) apontou a palavra cultura como a melhor forma de se definir Paideia, Jaeger escreve que o fenômeno não pode ser contemplado com olhos do homem moderno. É necessário, em seu pensamento que os gregos em seus próprios termos, com olhos do homem que viveu experimentou aquela época. Assim sendo, nenhuma expressão moderna como civilização, tradição, ou mesmo cultura, explicam de maneira inequívoca o que os gregos entendiam por Paideia, pois cada um dos termos citado é apenas uma face do complexo fenômeno grego. De forma a iniciar uma explanação sobre o tema, se faz necessário, portanto, entender que a Paideia não era para os gregos um aspecto exterior à vida, mas a formação do homem em contato orgânico com a cultura em um esforço a ser realizado por toda vida (JAEGER, 2013). 
O estudioso italiano Franco Cambi (1999), escreve que antes mesmo d desenvolvimento do conceito de Paideia, já existiam dois modelos de formação humana que poderiam ser relacionadas às tragédias e à medicina grega. Contudo, será com a Paideia desenvolvida entre os filósofos no período clássico (séculos V e IV a. C) que atestará o surgimento da pedagogia como episteme, não mais como ethos ou como praxis apenas. Entre os modelos desenvolvidos, estão os de Sócrates, Platão e Aristóteles.

A paideia de Sócrates tem como componente principal a relação entre mestre e aluno. O primeiro é o responsável por realizar as questões, suscitar dúvidas e solicitar pesquisas, cabendo ao segundo responder ao mestre. Mestre e aluno constroem o processo dialético por meio da oposição e unificação das ideias, aprofundando determinado saber que visa o "trazer para fora" e o "conhece a ti mesmo", realizando o princípio da liberdade e da universalidade nos jovens (MANACORDA, 1992).

Platão sabia que a Paideia tinha uma significação política e que a transmissão dos valores e da cultura grega tornava a educação a mais importante das magistraturas do Estado. Assim sendo, Platão idealiza dois modelos de Paideia, segundo escreve Franco Cambi (1999). O primeiro modelo, de inspiração socrática, foi idealizada nas obras Fédon, Fedro e $O$ Banquete. A proposta consiste em uma elevação da alma que se inicia na beleza dos corpos, isto é, no sensível, no material, e segue em crescimento em direção ao entendimento da ideia de beleza, ou seja, da belza em si e do bem viver em sociedade. O segundo modelo, encontrado em $A$ República e As Leis, Platão hierarquiza a sociedade em três classes sociais: os produtores, os guardiões-guerreiros e os governantes filósofos. A educação dos produtores aconteceria no local de trabalho, obedecendo a critérios técnicos. Os guardiões seriam treinados em instituições públicas, sendo oferecida uma educação musical e literária, sem o aprofundamento dos discursos. Mais tarde, os guardiões que se revelassem mais aptos ao estudo da dialética eram aproveitados, habituando-se a pensar de forma abstrata, elevando sua alma para a contemplação e futuramente assumindo os cargos do governo. 
A proposta de Aristóteles, por outro lado, apresenta como mais realista, característico de sua filosofia. Aristóteles busca em sua proposta a plenitude do ser e a realização de suas potências. Para isso, enfatiza uma pedagogia da essência, voltada para a imitação e repetição como construtora da virtude, presente no justo meio. Aristóteles, no entanto, também divide a sociedade em classes: o povo e os nobres, sendo que apenas esses últimos deveriam receber educação do Estado, pois apenas

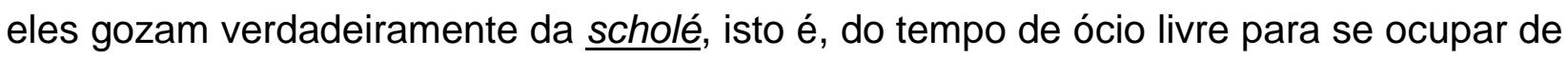
estudos.

Esse novo 'anthropos', cujas relações são horizontais, segundo Aristóteles, é o zoon politikon, que prioriza o diálogo na figura da política, ao invés da força, figurada na polícia ou na violência (CANIVEZ, 1991). Dessa maneira, para Wagner Jaeger (2013), a Paideia é a formação espiritual mais elevada que se poderia dar ao homem grego, realizando um ideal de formação democrática, fundamentada na comunidade dos cidadãos livres do Estado.

Em Ética a Nicômaco, Aristóteles (2006) aponta que a primeira função da vida é nutrir-se. Tal afirmação diz respeito à ética grega de busca pelo sagrado e pelo bem por meio do conhecimento. Aristóteles também aponta que o logos, o bem público e a boa vida em sociedade podem ser alcançados pela práxis de atos virtuosos. Nesse sentido, o exercício constante de ações virtuosas deve levar a um círculo virtuoso capaz de construir uma existência de bem-estar e felicidade.

Aristóteles planejou sua proposta de Paideia a partir da evidência experimentada de que após Atenas sucumbir diante de Esparta, uma crise moral e política tomou conta da cidade. O juízo de que o homem deveria simplesmente se deixar ser tomado pelos seus desejos, anseios e vontades, geraram uma grande instabilidade na polis ateniense, na perspectiva do Estagirita. A partir desse desequilíbrio, com uma degradação dos valores morais gregos, a corrupção, os golpes de Estado, as traições políticas e até mudanças nas práticas sexuais das classes hegemônicas gregas 
passaram a fazer parte do cotidiano, havendo a partir daí, uma inversão do círculo virtuoso proposto por Aristóteles.

Para Aristóteles, enquanto os instintos são matéria bruta da moral, a cultura e a prática de atos virtuosos, por outro lado, seriam as únicas coisas capazes de promover o refinamento dos homens. A rex, isto é, o hábito de seguir as leis, levaria o homem a ter verdadeira aversão pelo que está fora da lei e conduziria o homem a conseguir controlar seus desejos, chegando ao estágio de 'contingente', imutável, incorruptível.

Pode parecer fácil, mas o caminho da virtude é tortuoso e difícil. O homem deve tentar durante muito tempo, inativando seu querer irracional até que seja recompensado por atingir sua meta, até atingir o gozo. Esse adestramento, repetição desta etapa até que ela se transforme em costume, é árdua e contínua. A recompensa deste costume vem com o surgimento de um 'hábito', onde as ações virtuosas já estão incorporadas ao cotidiano do homem. Antes de atingir esse ponto, antes de chegar a esse prazer, o sentimento de angústia poderia tomar o homem por diversas vezes. Contudo, como sinalizou Aristóteles, ainda restariam na sociedade os chamados homens 'intemperantes', ou como colocou o ministro do Supremo Tribunal Federal recentemente, homens com "uma mentalidade com um ciclo civilizatório incompleto" (BARROSO, 2020. In: Roda Viva). Em outras palavras, homens que mesmo depois de exercitar e repetir por diversas vezes a práxis que os conduziriam a virtude, apenas teriam consciência da lei, continuando a vida sem terem força para agir em sua conformidade.

Assim sendo, diante de uma série de transformações do ser social brasileiro na atualidade, vale a pena abordarmos a concepção de virtude usada na obra de Aristóteles. Com isso, temos o objetivo de refletir sobre o que é o bem viver em sociedade e pensar sobre como essa proposta desenvolvida na antiguidade pode se transformar em uma prática virtuosa nos dias atuais. 


\section{A CONCEPÇÃO DE VIRTUDE}

De maneira mais abrangente é possível considerar que a virtude é uma capacidade da alma, uma ação, ou uma força da alma. A alma, por sua vez, é intrinsecamente ligada ao homem tal como o corpo, que por muitas vezes não responde as vontades do próprio homem. Essa divisão entre corpo e alma, segundo o pensamento filosófico clássico se torna necessária para que seja possível buscar o entendimento de si mesmo. A própria alma também deve ser dividida em duas: a alma irracional, vegetativa e sensitiva, e a alma racional. A alma vegetativa caberia a todos os seres vivos, sendo a responsável por guiar os princípios ligados a alimentação, a manutenção da vida e a perpetuação da espécie. Já a alma sensitiva tem relações com os sentidos, sendo, portanto, responsável pelo apetite, pelo desejo. A segunda forma da alma, a racional, ou intelectual, está tanto ligada às realidades universais, quanto está ligada as capacidades da práxis com fins de busca pela virtude (razão deliberativa).

Em sua obra, Aristóteles divide a virtude em dois grandes grupos: a Virtude dianoética e a Virtude ética. A virtude dianoética aponta para a intelectualidade, também para a força de pensamento (EN, II, 1, 1103a). Nesse grupo, ao lançar mão da alma racional, o homem só se tornaria virtuoso quando ganhar força e combater a si próprio no que diz respeito aos seus instintos. Finalmente, o homem poderia aprisionar a sua intemperança e a parte irracional de sua alma. Esse difícil exercício da intelectualidade, como proposta de capacitação do homem para o entendimento da vida em sociedade, se desenvolve, em primeiro lugar, na capacidade do homem, por si só, de se transformar e buscar a virtude. Contudo, para esse trabalho, nos concentraremos nas virtudes éticas e na práxis visando exemplificar os caminhos que nossa sociedade pode tomar em direção a boa vida em sociedade.

Ao tratar da Virtude ética, que diz respeito às ações e as práticas dentro do mundo (Ética a Nicômaco - EN, I, 9, 1099b), Aristóteles aponta sempre para a busca de 
um meio-termo como caminho para a sua conquista. Nos concentraremos na próxima parte em abordar os tipos de virtudes, destacando o meio-termo, em contraste a intemperança e a incontingência. $O$ pensamento aristotélico sagra o meio-termo como ponto ideal de busca do homem em se tornar virtuoso, apresentado suas extremidades, para mais ou para menos, como vícios.

\section{AS VIRTUDES ÉTICAS}

\section{A coragem}

(...) o homem corajoso escolhe e enfrenta coisas porque é nobre fazê-lo, ou porque é vil deixar de fazê-lo. Porém, morrer para fugir à pobreza, ao amor, ou a quaisquer coisas dolorosa, não é próprio de um homem corajoso, mas sim de um covarde (...). (ARISTÓTELES, 2006, 1116.a.10-14)

A 'coragem' é a primeira das virtudes apresentadas por Aristóteles, a qual podemos identificar como uma virtude ética. O filósofo aponta que temer determinadas coisas é justo e nobre. Temer a morte, a desonra, a falta de amigos é próprio ao homem de coragem.

O homem corajoso se mostra destemido em face de uma morte honrosa, no cumprimento de seu dever. Por exemplo, é normal que um soldado na guerra tema sua morte. Isto é considerado saudável, pois o medo de morrer em batalha o ajuda a manter-se vivo. O medo que ele sente, no entanto, não pode ser maior do que a sua função-militar e a sua vontade de proteger sua cidade. Nessas circunstâncias, caso ele morra em batalha para proteger sua sociedade, isso demostrará coragem e desapego a vida.

Por outro lado, o homem que não teme a desonra e a morte, é um homem temeroso, pois é capaz de agir em dissonância com as leis e as relações sociais da polis. Nenhum homem deve temer demais pela sua vida, nem ser excessivamente destemido, ao ponto de não temer pela sua morte. 
Aristóteles considera também o conhecimento, por meio da experiência com relação a uma determinada situação de perigo, um tipo de ação pertinente a coragem. Sobre isso, os soldados experientes são grandes exemplos deste tipo de conhecimento. A paixão, outro tipo de ação pertinente a coragem, funciona como diferenciador do homem dos demais animais, pois enquanto os primeiros agem em vista da honra, os segundos agiriam conforme a dor ou o sentimento de ameaça. Contudo, mesmo aqui, o filósofo salienta o meio-termo, pois "não são consideradas corajosas as pessoas que são impelidas ao perigo pelo sofrimento ou paixão". A emoção, pode também funcionar como ação para a coragem. Porém, apenas quando tem por finalidade a honra. As pessoas otimistas, da mesma forma, quando demonstram excesso de confiança diante do perigo, não são corajosas. Contudo, o homem que age em conformidade com os méritos, age com otimismo e, portanto, age com coragem. A ignorância, nesse sentido, não está muito distante do otimismo, pois aquele que se equivoca quanto a realidade e toma conhecimento do fato posteriormente, foge como um otimista que perdeu a confiança em sua posição.

A honra, o conhecimento, a paixão, o otimismo e a ignorância, juntos descrevem o caráter dos homens corajosos e daqueles que se consideram corajosos. Aqui, portanto, o meio-termo como virtude, aponta Aristóteles é a 'coragem'.

\section{A temperança}

(...) no homem temperante o elemento apetitivo deve harmonizar-se com o princípio racional, pois o objetivo de ambos é o nobre, e o homem temperante deseja as coisas que deve desejar, da maneira e na ocasião certas; e isso é o que determina o princípio racional. (ARISTÓTELES, 2006, 119.b. 16-19)

O segundo tipo de virtude que podemos considerar ética é a temperança. A temperança é o meio-termo entre o excesso nos relacionamentos de prazer obtidos através dos sentidos humanos, embora Aristóteles também faça referência a diferenciação dos prazeres obtidos pela alma. Entre todos os sentidos, alguns não 
podem ser ligados aos excessos ou a carência, como é ocaso da visão, o olfato ou da audição. Por outro lado, o comer excessivo, considerado a mais difundida dentre essas intemperanças, é caracterizado pelos homens que enchem o estômago além da medida. Quanto a intemperança promovida pelo excesso de prazer gerado pelo tato ou pelo toque, o homem perde a capacidade de discernir entre o que é bom e o que é demais, buscando o prazer custe o que custar nas coisas e nas relações em sua vida.

Desta forma, aquele que não é temperante, que não busca o meio-termo nas relações sensíveis consigo mesmo, anseia por todas as coisas prazerosas durante todo tempo. Com efeito, o intemperante também sofre quando não consegue atingir seus anseios. Isto é, o excesso pode lhe causa ansiedade e a falta pode lhe causar dor.

Aristóteles assim aponta que a virtude da temperança se destaca no homem que não sofre e não anseia quando as coisas Ihe faltam. Ele ocuparia uma posição mediana em relação aos objetos de desejo. Mesmo as coisas que contribuem para a sua saúde e para a boa condição do corpo, o homem temperante de pretender busca-las dentro de uma condição de meio-termo. Não mais, nem menos, o homem deve alimentar apetites poucos e moderados, sem se opor ao princípio do racional. Uma relação de obediência e disciplina, de busca pela entrada no círculo virtuoso.

\section{A liberalidade}

Aparentemente ela é o meio-termo em relação à riqueza, pois o homem liberal é louvado não pelos seus feitos militares, nem pelas coisas que se costuma louvar no homem temperante, nem por decidir com justiça em um tribunal, mas em relação a dar e obter riquezas - sobretudo a dá-las (ARISTÓTELES, 2006, 1119.b.21-25).

No que se refere ao uso da virtude liberdade, é necessário destacar a diferença da concepção de liberdade ocidental da atualidade, que está relacionada a liberdade de decisão sobre a própria vida. Muitas pessoas no ocidente relacionam tal ideia de liberdade ao acúmulo de riquezas e acúmulo de poder visando a decisão sobre 
processos relacionados as vidas de outras pessoas. Mas virtude da liberdade tem outras origens no pensamento aristotélico.

$\mathrm{Na}$ Grécia antiga, a liberdade referia-se ao uso da própria riqueza. Nesse sentido, a prodigalidade e a avareza são, respectivamente, o excesso e a deficiência no que the diz respeito. O homem virtuoso de liberdade oferece aos outros aquilo que tem e pode, portanto, dar de bom grado e sem sofrimento. Procura também oferecer o que pode às pessoas certas, na hora certa. Isto faz com que suas ações ganhem em prazer, isentando-o de sofrimento.

Os recursos do homem livre provêm sempre de ações idôneas, ou seja, provém sempre de seus próprios meios, que são invariavelmente lícitos e legais. Deve-se destacar que a virtude reside não nas posses, mais na disposição de caráter em dar de acordo com as suas dádivas. Aristóteles cita o exemplo de um presente realizado para uma criança. Tratava-se de uma bela bola, porém, simples e barata. Assim, considerando as possibilidades e o nível de riqueza do homem que ofertou o presente, a bola pode ser considerada uma ação que revela virtude.

Por outro lado, o prodigioso oferece além do que tem e pode, dando para as quais não deve. $O$ avarento, também incorre no erro do excesso, preferindo ficar com sua riqueza a agir nobremente, acumulando recursos, ao invés de distribuir àqueles que precisam. O prodigioso excede-se em dar e não obter e o avarento em obter e não dar. Vemos assim, que o ato virtuoso de dar e receber estão presentes naqueles que mantém a virtude da liberdade. A esse homem, será conferida a idéia de que dá e gasta as quantias certas com os objetos certos, quer sejam coisas pequenas ou grandes, agindo sempre com prazer.

\section{A magnificência}

(...) o magnificente em cada caso é o que é grandioso na circunstância específica deste, e a grandeza da obra difere da grandeza do dispêndio (...) Por outro lado, o homem mesquinho fica aquém da medida em tudo, e depois 
de gastar grandes somas estraga a beleza do resultado por causa de uma ninharia (...) (ARISTÓTELES, 2006, 1123.a.15-300).

Bem como a liberdade, a magnificência também é ligada a riqueza. $O$ homem magnificente sabe gastar apropriadamente as suas riquezas. Os resultados de seus gastos são, em contrapartida, também grandiosos, sempre em vista da honra, pois assim como Aristóteles escreve, esse é o fim de todas as virtudes. Desta forma, a magnificência é um atributo dos gastos que são chamados de honrosos.

Esta virtude parece estar ligada principalmente as classes sociais mais abastadas das cidades gregas, pois Aristóteles escreve que seus gastos, voltados para honra, se relacionam com os deuses, como por exemplo, a construção de templos, as oferendas votivas, os sacrifícios, a organização de coros, entre outros. Há de se destacar que todos esses são objetos da ambição cívica. O homem magnificente não gasta consigo mesmo, mas sim com os objetos públicos.

Porém, assim como no caso da liberdade, a proporção dos gastos deve ser relacionada como a posição daquele que pretende essa virtude. O filósofo destaca então que o homem pobre, aparentemente, pode vir a ter limitações em tentar ser magnificente. No entanto, mantem-se a ideia aqui de doar para a comunidade ou para a sociedade aqui é possível para a sua realidade.

Assim sendo, o excesso leva o homem a se tornar extravagante e vulgar, pois gasta além do que é justo, com objetos que não deveria. Em contraposição, o homem mesquinho, como já apontamos, hesita em tudo que faz, estudando para gastar menos, lamentando o pouco que já gastou e julga estar fazendo tudo em maior proporção do que deveria nessa vida.

\section{A magnanimidade}

Deve ser incapaz de viver em função de outras pessoas a não ser que se trate de um amigo, pois isso é próprio de um escravo, e por isso são subservientes todos os aduladores, e aduladores todos aqueles que não respeitam a si próprios. Tampouco é propenso à admiração, pois nada é grande para ele. 
Nem guarda rancor por ofensas que lhe façam, visto não ser próprio de um homem magnânimo ter memória longa, sobretudo no que concerne a ofensas, que é melhor revelar. Ele também não é dado a conversas fúteis; não fala nem de si mesmo nem dos outros, pois não lhe interessam nem os elogios que the possam fazer nem as censuras dirigidas aos outros; nem é amigo de elogiar nem de falar mal dos outros, nem mesmo dos seus amigos, salvo por desdém (ARISTÓTELES, 2006, 1125.a.1-10).

Para ser magnânimo, o homem precisa estar à altura de coisas grandiosas. Trata-se aqui da busca pela grandeza da alma. Para Aristóteles, aquele que tem tal capacidade, mas, no entanto, não se julga capaz de coisas grandiosas é tachado como um tolo. Já o que vai além das suas capacidades, pode ser visto como insensato. É possível perceber que, da mesma forma que na magnificência, são magnânimos aqueles que tem disposição para coisas relacionadas à honra e a desonra. Novamente percebemos uma virtude ligada as altas classes sociais helênicas, pois para tanto é necessário não só ter muitas posses, mas também desfrutar delas em favor público.

O magnânimo também possui a qualidade de conferir benefícios moderadamente, embora não peça nada para si. Desta forma, a magnanimidade está ligada a uma série de outras virtudes, tornando-se difícil alcançá-la verdadeiramente. Será necessário para ser magnânimo, possuir um caráter bom e nobre.

Também aqui o meio-termo é indicado entre o excesso de humildade e a arrogância de exceder na declaração de méritos próprios. O homem magnânimo não se rejubilará excessivamente com a boa fortuna nem sofrerá excessivamente com a má. Portanto, ele jamais ficará aquém, sendo indevidamente humilde, nem ficará em excesso, ficando pretensioso, ou seja, além do que deve ser.

\section{A honra, a calma e o espirituoso}

Em relação à honra, Aristóteles também destaca a existência de uma deficiência e de um excesso. Censura-se aqui o homem que é ambicioso demais, procurando a honra a todo custo. Também é altamente censurável aquele que não tem pretensões de 
ter honras, pois este é um homem que não quer alcançar a virtude e por isso é execrável.

A calma é um meio termo em relação à passividade e a violência. Aquele que é pacato demais é incapaz de se defender e defender sua família ou sua cidade, caracterizando-se assim uma falta grave naquele que busca a virtude. O filósofo aponta isso como uma característica de escravos, pois estes deveriam suportar insultos sem se defender. Por outro lado, os homens facilmente encolerizáveis irritam-se com qualquer coisa, devendo se arrepender depois de suas ações intempestivas.

Aqueles que levam o humor ao excesso, humilhando as outras pessoas ou colocando-as em posição de incômodo, são consideradas bufões vulgares. Estes, na ânsia de fazer os outros rirem e de se colocar no centro das atenções de todos, não atingem a virtude, pois se colocam sobre outras pessoas. Aquele que, por outro lado, não tem humor nenhum, dificulta a vida em sociedade, pois é impossível ficar perto de um homem que se lamenta ou está de cara fechada o tempo todo. O meio-termo exposto pelo filósofo é o homem espirituoso, capaz de gracejar com bom gosto.

\section{A justiça}

A justiça é provavelmente a maior preocupação quanto a virtude na obra de Aristóteles e devemos aproveitá-la para finalizar este artigo, ressaltando a sua importância como relação social capaz de manter uma sociedade coesa.

A cidade tem sua origem no fato de os homens não serem auto-suficientes. Lembramos a peça de Ésquilo, A trilogia de Orestes, onde podemos perceber claramente a passagem de uma justiça baseada na vingança, ou seja, intrafamiliar, para uma justiça baseada em leis criadas por uma instituição maior que a familiar, a instituição da justiça da polis.

Nas famílias, para suprir suas necessidades, associam-se, reunindo-se em um mesmo território e dividindo entre si as tarefas visando a subsistência. Deste modo, o 
lavrador irá cuidar da alimentação, o pedreiro da habitação, o tecelão do vestuário e assim por diante cada um compartilhando com os demais o fruto de seu trabalho. Além disso, cada um deve se limitar à execução de uma tarefa determinada, àquela para a qual possui aptidão natural. Já na organização de uma cidade-estado, para além dos trabalhadores, alguns homens devem ser encarregados de cuidar da defesa e ordem da polis. Tal como encontramos em Platão, que escreve que "o guardião deve ser como um cão de boa raça, dotado ao mesmo tempo de mansidão e de ousadia; deve ser forte e ágil no físico, irascível, valente e amante do saber da alma", a filosofia de Aristóteles também encontra aqui o seu meio termo: a justiça.

Quanto à justiça, portanto, ela está definida pelo preceptor de Aristóteles como "a posse do que pertence a cada um e a execução do que lhe compete ${ }^{3}$ ". Se for válida a suposição ao de que o Estado representa o homem em escala ampliada, então as três classes constituintes da cidade ideal platônica deverão ser encontradas no homem. Elas associam-se às três faculdades da alma: a racional, a irascível e a apetitiva. Por analogia, a justiça no indivíduo é "a disposição, das faculdades da alma que faz com que cada uma cumpra a função que lhe é própria, e, de acordo com a sua natureza, domine ou se deixe dominar, ela é algo que diz respeito não à atividade exterior, mas à interior, ou seja, à própria vida da alma (REALE, 2007, p. 251)".

\section{CONSIDERAÇÕES FINAIS}

A vida em sociedade, portanto, só será possível com uma justiça atuante em seu equilíbrio e com homens virtuosos dentro da perspectiva apontada por Aristóteles. Uma relação entre os indivíduos educados para a vida em sociedade e um Estado que espelhe a justiça aos cidadãos. A crise que o Brasil enfrenta nos dias atuais, está bem exemplificado nos casos de deficiência de todas as virtudes apontadas, sendo isso um efeito do que é observado em falta também no Estado.

\footnotetext{
${ }^{2}$ Platão. República. [12], p. 245.

${ }^{3}$ Idem. 433e.
} 
Platão aponta ainda que para constituir cidadãos é necessária uma educação muito acurada, tanto do corpo quanto da alma. Por sua vez, a obra de Aristóteles afirma que também é necessário distinguir governantes e governados. Os governantes deveriam ser escolhidos entre os melhores guardiões. Ao adaptarmos esse pensamento aos dias de hoje, podemos dizer que os governantes deveriam ser aqueles mais preocupados em proteger a lei e aqueles que dependem mais da lei. De toda forma, com base no que desenvolvemos sobre o pensamento de Aristóteles, é válido afirmar que o bem viver em sociedade exigiu na antiguidade uma postura virtuosa a ser exercitada como hábito desde a mais tenra idade até o fim da vida, conforme proposto na Paideia do filósofo.

\section{REFERÊNCIAS}

ARISTÓTELES. Ética a Nicômaco. Edtora Martin Claret. São Paulo, 2006.

CAMBI, Franco. História da Pedagogia. São Paulo: Editora da Unesp, 1999.

CANIVEZ, Patrice. Educar o cidadão? Campinas: Papirus, 1991.

CHARLOT, Bernard. A mistificação pedagógica. Rio de Janeiro: Jorge Zahar, 1979.

ESQUILO. A Trilogia de Orestes. São Paulo: Ediouro, 1988.

JAEGER, Werner. Paideia: a formação do homem grego. São Paulo: Martins Fontes, 2013.

MANACORDA, M. História da Educação: da Antiguidade aos nossos dias. São Paulo: Cortez, 1995.

MARROU, Henri-Irénée. História da educação na antiguidade. São Paulo. EPU Edusp. 1973.

MATOS, Olgária. Filosofia: a polifonia da razão. São Paulo: Scipione, 1997.

PLATÃO. A República. Lisboa: Fundação ao Calouste Gulbenkian, 1987.

RODA VIVA. Entrevista com Luís Roberto Barroso. 15 de jun. de 2020. Disponível em: https://www.youtube.com/watch?v=gxDsgIWkVJQ. Acessado dia 6 de ago. de 2020. 


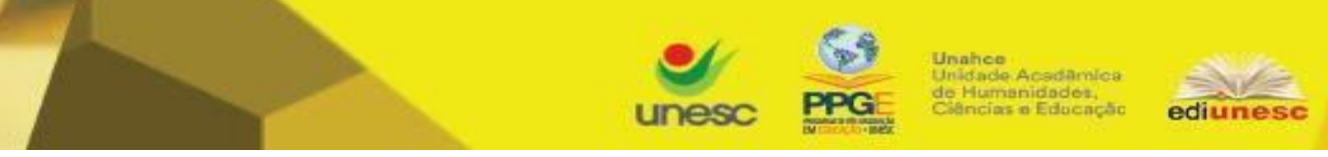

Criar Educação, Criciúma, v. 10, nº1, jan/jul 2021.- PPGE - UNESC - ISSN 2317-2452

REALE, Giovanni. História da Filosofia Grega e Romana - Platão. Trad. Henrique Cláudio de Lima Vaz e Marcelo Perine. 10. Ed. São Paulo: Loyola, 2007.

Recebido novembro de 2020 Aprovado março de 2021 